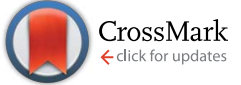

Cite this: RSC Adv., 2016, 6, 38342
Received 11th March 2016

Accepted 6th April 2016

DOI: $10.1039 / c 6 r a 06555 d$

www.rsc.org/advances

\section{Lifetime limit of tris(trimethylsilyl) phosphite as electrolyte additive for high voltage lithium ion batteries}

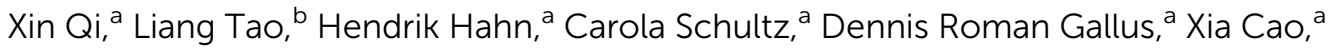 \\ Sascha Nowak, ${ }^{a}$ Stephan Röser, ${ }^{a}$ Jie Li, ${ }^{a}$ Isidora Cekic-Laskovic, ${ }^{\text {*a }}$ \\ Babak Rezaei Rad*ac and Martin Winter ${ }^{\star a c}$
}

\begin{abstract}
The tris(trimethylsilyl) phosphite (TMSPi) is considered as an ideal electrolyte additive for lithium ion batteries. In this work, its positive effect as well as its failure mechanism in a LiPF 6 containing electrolyte was studied by means of selected electrochemical, structural and analytical techniques. The $\mathrm{LiNi}_{0.5} \mathrm{CO}_{0.2} \mathrm{Mn}_{0.3} \mathrm{O}_{2} /$ graphite cells with TMSPi as electrolyte additive were cycled between 2.8 and $4.6 \mathrm{~V}$. Thanks to the compact cathode electrolyte interphase formed by the oxidative decomposition of TMSPi in a freshly prepared TMSPi containing electrolyte, both the discharge capacity and the cycling stability of cells were enhanced. However, our results also show that TMSPi actually reacts with $\mathrm{LiPF}_{6}$ at room temperature. TMSPi is consumed by this spontaneous reaction after aging for certain time. In addition, a part of the fluorophosphates, generated from the hydrolysis of $\mathrm{LiPF}_{6}$, is bonded to one or two TMS groups, causing a decrease in the fluorophosphate content in the CEI film. Consequently, the cycling stability of the lithium ion cells with aged TMSPi containing electrolyte deteriorates. The obtained results offer important insights into the practical application of TMSPi, which means that TMSPi can only be used as an effective additive in a freshly prepared $\mathrm{LiPF}_{6}$ containing electrolyte.
\end{abstract}

\section{Introduction}

To facilitate the robust development of hybrid electric vehicles (HEVs) and electric vehicles (EVs), lithium ion batteries (LIBs), as one of the most promising energy supplies, are expected to provide "high voltage" (>4.5-4.6 V) to enhance their energy density. A variety of cathode materials with high working potential has been reported so far. However, they are rarely used in commercial cells, mainly due to the poor electrochemical oxidation stability of the traditional $\mathrm{LiPF}_{6}$ containing carbonate based electrolytes at these high voltages. ${ }^{1,2}$ The oxidative decomposition of the carbonate solvents has been confirmed to produce $\mathrm{H}_{2} \mathrm{O}$ and $\mathrm{CO}_{2} \cdot{ }^{3}$ The generated $\mathrm{H}_{2} \mathrm{O}$ further promotes the hydrolysis reactions of $\mathrm{LiPF}_{6}$ to generate $\mathrm{HF},{ }^{4}$ which induces serious damage of metal oxide cathodes ${ }^{5,6}$ and the solidelectrolyte interphase (SEI) on the graphite anodes. ${ }^{7}$ An economic way to prevent the oxidation of the traditional electrolyte formulations at high voltage is to use specific electrolyte additives to form a cathode-electrolyte interphase (CEI), ${ }^{5,8}$

${ }^{a}$ MEET Battery Research Center, Institute of Physical Chemistry, University of Münster, Corrensstrasse 46, 48149, Münster, Gemerny

${ }^{b}$ Amperex Technology Limited, No. 1 XinGang Road, JiaoCheng District, 35210, Ningde, China

${ }^{c}$ Helmholtz Institute Münster, IEK-12 of Forschungszentrum Jülich, Corrensstrasse 46, 48149, Münster, Germany stabilize the electrolyte salt, ${ }^{9}$ scavenge the corrosive impurities $\left(\mathrm{HF}, \mathrm{PF}_{5}\right),{ }^{10}$ or to remove the $\mathrm{O}_{2}$ gas evolved from the cathode material. ${ }^{\mathbf{1 1}}$

Similar to the SEI formed on the graphite anode, the CEI is considered as an essential protective layer on the cathode surface that helps to prevent further oxidative decomposition of the electrolyte. ${ }^{12}$ However, a thick CEI film may deteriorate the cell performance by increasing the interfacial impedance, in particular when it contains more highly resistive components, ${ }^{\mathbf{1 3}}$ e.g. LiF. CEI formation additives are expected to produce a robust and thin CEI layer to enhance both the cycling stability and rate capability. ${ }^{\mathbf{1 4}}$

Tris(trimethylsilyl)phosphite (TMSPi, shown in Scheme 1), has been introduced as an effective bifunctional additive to build a CEI upon its oxidative decomposition as well as to scavenge the HF generated during cycling. ${ }^{15}$ The cycling stability of $\mathrm{LiNi}_{0.5} \mathrm{Mn}_{1.5} \mathrm{O}_{4}$ (ref. 16) and $\mathrm{LiNi}_{1 / 3} \mathrm{Co}_{1 / 3} \mathrm{Mn}_{1 / 3} \mathrm{O}_{2}$ (ref. 15 and 17) cathodes at high potential $\left(\geq 4.5 \mathrm{~V}\right.$ vs. $\left.\mathrm{Li} / \mathrm{Li}^{+}\right)$was significantly improved by $0.5 \mathrm{wt} \%$ TMSPi in the electrolyte. Yim et al. ${ }^{18}$ calculated the oxidation potential (OP) and the reduction potential (RP) based on the Kohn-Sham density functional theory (DFT): TMSPi has an OP as $4.29 \mathrm{~V} v s$. $\mathrm{Li} / \mathrm{Li}^{+}$, lower than the OP of ethylene carbonate (EC, $6.92 \mathrm{~V} v s . \mathrm{Li} / \mathrm{Li}^{+}$). On the other hand, the RP of TMSPi is much lower than EC. ${ }^{18}$ Consequently, the TMSPi would easily undergo an oxidative decomposition on the cathode but less probable reductive decomposition on the 


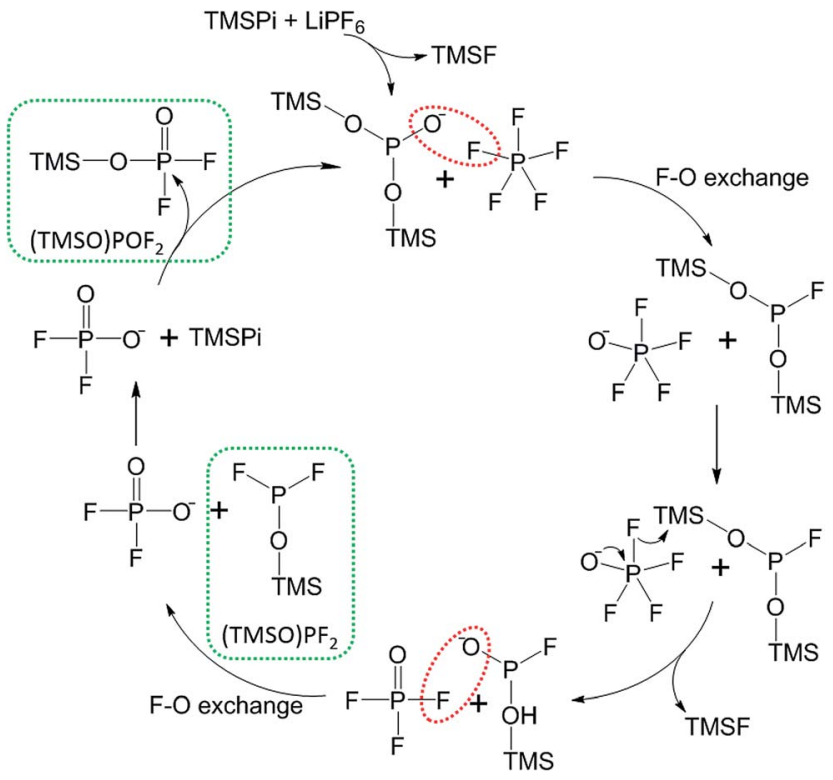

Scheme 1 A proposed mechanism for the reaction of TMSPi with $\mathrm{LiPF}_{6}$, without the participation of $\mathrm{O}_{2}$ and $\mathrm{H}_{2} \mathrm{O}$. The formation of (TMSO)PF $F_{2}$ and (TMSO)POF 2 is taken as example.

anode. A CEI film can thus be formed to prevent transition metal ion dissolution from the cathode and further oxidative decomposition of the electrolyte. ${ }^{15}$ Simultaneously, the trimethylsilyl (TMS) group shows high binding affinity towards HF owing to the formation of a strong Si-F bond. For this reason, TMSPi is also considered as a HF scavenger.

Besides $\mathrm{Me}_{3} \mathrm{SiF}$ (TMSF), two more decomposition compounds: $\mathrm{Me}_{3} \mathrm{SiOH}$ (TMSOH) and $\mathrm{Me}_{3} \mathrm{SiOSiMe}_{3}$ (TMSOTMS) have also been observed in the ${ }^{1} \mathrm{H}-\mathrm{NMR}$ spectra of the TMSPi-containing electrolyte, ${ }^{18}$ indicating that the highly electrophilic TMS group acts not selectively as a $\mathrm{F}^{-}$receptor, but rather as an receptor for all anions. Hence, it can be suspected that TMSPi may also directly react with the $\mathrm{LiPF}_{6}$ salt or with the hydrolysis reaction products of $\mathrm{LiPF}_{6}$. After a certain aging period, the HF scavenging effect of the electrolyte additive may vanish as all TMSPi molecules are continuously consumed by this chemical reaction. In this work, we studied the spontaneous reaction between TMSPi and $\mathrm{LiPF}_{6}$ and we could identify the products by various analysis methods, including gas chromatography-mass spectrometry (GC-MS) and nuclear magnetic resonance (NMR) spectroscopy. We also investigated the electrochemical performance of the TMSPi containing electrolyte in a $\mathrm{LiNi}_{0.5} \mathrm{Co}_{0.2} \mathrm{Mn}_{0.3} \mathrm{O}_{2} /$ graphite full cell at high cutoff voltage $(4.6 \mathrm{~V})$. The oxidation stability analysis revealed that the aged TMSPi containing electrolyte failed to form a protective CEI on the cathode. A detailed interaction between TMSPi and $\mathrm{LiPF}_{6}$ is shown in this work.

\section{Experimental}

\section{Electrolyte and electrode preparation}

A $3: 7$ (weight ratio) mixture of ethylene carbonate (EC) and diethyl carbonate (DEC) with $1 \mathrm{M} \mathrm{LiPF}_{6}$ was used as baseline electrolyte (LP47, UBE, $\mathrm{H}_{2} \mathrm{O}$ content $\leq 10 \mathrm{ppm}$ ). 0.5 wt $\%$ TMSPi was added into the baseline electrolyte in an argon filled glovebox (Braun, $\mathrm{H}_{2} \mathrm{O}$ and $\mathrm{O}_{2}$ content $\leq 0.1 \mathrm{ppm}$ ). The "fresh TMSPi containing electrolytes" were prepared shortly prior to each measurement. The "aged TMSPi containing electrolytes" were stored in glovebox at $20{ }^{\circ} \mathrm{C}$ for different time periods ranging from 12 hours to 2 months.

$\mathrm{LiNi}_{0.5} \mathrm{Co}_{0.2} \mathrm{Mn}_{0.3} \mathrm{O}_{2}$ and graphite were used as cathode and anode active materials, respectively. Li metal (Rockwood Lithium ${ }^{\circledR}$, lithium battery grade) was used as reference electrode (Ø $6 \mathrm{~mm}$ ). The cathode was composed of $97 \mathrm{wt} \% \mathrm{LiNi}_{0.5} \mathrm{Co}_{0.2^{-}}$ $\mathrm{Mn}_{0.3} \mathrm{O}_{2}$ (ATL), $2 \mathrm{wt} \%$ carbon black (Super $\mathrm{P} \mathrm{Li}{ }^{\circledR}$, Amerys) and $1 \mathrm{wt} \%$ polyvinylidene difluoride (PVdF, Solef 5130, Solvay) as binder. The anode was constituted of $95.4 \mathrm{wt} \%$ graphite (ATL), $1.5 \mathrm{wt} \%$ Super $\mathrm{P} \mathrm{Li}{ }^{\circledR}$ and $3.1 \mathrm{wt} \%$ binder. This binder was a mixture of styrene butadiene rubber (SBR, Lipaton SB 5521, Synthomer) and sodium carboxymethyl cellulose (CMC, Walocel CRT 2000 PPA 12, Dow Wolff Cellulosics ${ }^{\circledR}$ ) with a weight ratio of $25: 6$. Both the cathode and anode electrodes were punched into round discs ( $12 \mathrm{~mm}$ ). The mass loading of the cathode was approximately $9.0 \mathrm{mg} \mathrm{cm} \mathrm{cm}^{-2}$, which meant the total amount of $\mathrm{LiNi}_{0.5} \mathrm{Co}_{0.2} \mathrm{Mn}_{0.3} \mathrm{O}_{2}$ was ca. $9.9 \mathrm{mg}$. To balance the cathode/ anode capacity ratio, the practical capacity of the $\mathrm{LiNi}_{0.5} \mathrm{Co}_{0.2^{-}}$ $\mathrm{Mn}_{0.3} \mathrm{O}_{2}$ cathode was first determined in the potential range from $2.8 \mathrm{~V}$ to $4.6 \mathrm{~V}$ vs. $\mathrm{Li} / \mathrm{Li}^{+}$with $\mathrm{Li}$ metal as counter electrode and a practical capacity of $197.5 \mathrm{~mA} \mathrm{~h} \mathrm{~g}^{-1}$ was obtained. The same procedure was applied to determine the practical capacity of the graphite anode between 0.01 and $1.5 \mathrm{~V} v s . \mathrm{Li} / \mathrm{Li}^{+}$, and a specific capacity of $334.5 \mathrm{~mA} \mathrm{~h} \mathrm{~g}^{-1}$ at $1 \mathrm{C}$ was obtained. The mass loading of the anode was controlled to have $25 \%$ extra capacity as the cathode. According to the mass loading of $\mathrm{LiNi}_{0.5} \mathrm{Co}_{0.2} \mathrm{Mn}_{0.3} \mathrm{O}_{2}$, the total amount of graphite on the anode side was ca. $7.3 \mathrm{mg}$. In the constant current charge/discharge cycling analysis, the specific current of $197.5 \mathrm{~mA} \mathrm{~g}^{-1}$ was defined as 1C. $200 \mu \mathrm{L}$ electrolyte was added into each cell. For each electrolyte formulation, at least three cells were assembled to ensure the reproducibility, which required a capacity deviation below $0.5 \mathrm{~mA} \mathrm{~h} \mathrm{~g}^{-1}$ between the parallel cells.

\section{Electrochemical analysis}

The cycling stability of the cells was analyzed in a three-electrode Swagelok® T-type cell. The cells were cycled on a Maccor ${ }^{\circledR}$ series 4300 battery cycler at $20{ }^{\circ} \mathrm{C}$. After three initial formation cycles at $0.1 \mathrm{C}$, the cells were charged/discharged at $0.5 \mathrm{C}$ in the following cycles. The oxidation stability of the electrolytes was determined by linear sweep voltammetry (LSV) performed by a VMP potentiostat (Biologic ${ }^{\circledR}$ Science Instruments). A platinum disc (Ø $1 \mathrm{~mm}$ ) was used as working electrode, whereas the counter and reference electrodes were both lithium metal discs $(\varnothing 12$ $\mathrm{mm}$ and $\varnothing 6 \mathrm{~mm}$, respectively). The scan range was set as 3.0$6.0 \mathrm{~V} v s$. $\mathrm{Li} / \mathrm{Li}^{+}$with a scan rate of $0.1 \mathrm{mV} \mathrm{s}^{-1}$.

\section{Qualitative analysis}

Qualitative GC-MS experiments were carried out on a GC-MSQP2010 Ultra System from Shimadzu® equipped with the AOC-5000 Plus autosampler from CTC Analytics. Separation

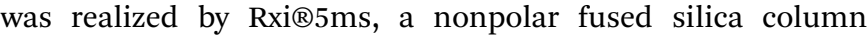


$(30 \mathrm{~m} \times 250 \mu \mathrm{m} \times 250 \mu \mathrm{m})$ from Restek®. Measurements were performed with helium (purity 6.0) from Westfalen AG as carrier gas. The headspace gas generated from the reaction between $\mathrm{LiPF}_{6}$ and TMSPi was equilibrated in an agitator at $120{ }^{\circ} \mathrm{C}$ for $120 \mathrm{~s}$ at $250 \mathrm{rpm} .1 \mathrm{~mL}$ gas was injected by a syringe at $120{ }^{\circ} \mathrm{C}$ and $500 \mu \mathrm{L} \mathrm{s}^{-1}$. After injection at $250{ }^{\circ} \mathrm{C}$, the following column oven program was executed and the sample measured in total for $20 \mathrm{~min}$. The temperature was kept at $35^{\circ} \mathrm{C}$ for $2 \mathrm{~min}$. and then increased to $60{ }^{\circ} \mathrm{C}$ with a rate of $3{ }^{\circ} \mathrm{C} \mathrm{min}{ }^{-1}$. Afterwards, the temperature increased to $250{ }^{\circ} \mathrm{C}$ with a rate of $31^{\circ} \mathrm{C} \mathrm{min}^{-1}$. The mass spectrometer was operated in the electron ionization (EI) mode with an $\mathrm{m} / \mathrm{z}$ scan range of 15-300. The ion source temperature was set to $250{ }^{\circ} \mathrm{C}$, the filament voltage to $70 \mathrm{~V}$ and the detector voltage relative to the particular tuning result. As software for compound identification and system control, GCMS Real Time Analysis and GC-MS Postrun Analysis, which included the National Institute of Standards and Technology (NIST) 08 library, were used.

The water content in the electrolyte was determined by the Karl-Fischer titration method. The measurement was performed by a combination of 801 stirrer and 851 titrado, acquired from Metrohm AG (Herisau, Switzerland).

Surface analysis of the $\mathrm{LiNi}_{0.5} \mathrm{Co}_{0.2} \mathrm{Mn}_{0.3} \mathrm{O}_{2}$ cathode was performed by X-ray photoelectron spectroscopy (XPS, Axis Ultra HAS, Kratos, GB) with a monochromatic Al $\mathrm{K}_{\alpha}$ source $(h v=$ $1486.6 \mathrm{eV}$ ) at a $10 \mathrm{~mA}$ filament current and a $12 \mathrm{kV}$ filament voltage source energy. Five positions were measured on each sample and each position had an area of $700 \mu \mathrm{m} \times 300 \mu \mathrm{m}$. The binding energy $(\mathrm{BE})$ of the $\mathrm{C} 1 \mathrm{~s}$ peak $(\mathrm{C}-\mathrm{C}, \mathrm{BE}=284.6 \mathrm{eV})$ was used as an internal reference to calibrate the spectra. All the cells were stopped after 150 cycles in the discharged state. The cathodes were removed out of the cells in a glovebox and transferred into the XPS chamber under argon protection.

To analyze the reaction products of TMSPi and $\mathrm{LiPF}_{6}, \mathrm{NMR}$ spectra were recorded on a Bruker Avance III $400(400.03 \mathrm{MHz}$, $\left.{ }^{1} \mathrm{H} ; 376.37 \mathrm{MHz},{ }^{19} \mathrm{~F} ; 161.93 \mathrm{MHz},{ }^{31} \mathrm{P}\right)$ spectrometer. All measurements were performed at $300 \mathrm{~K}$. Chemical shifts $(\delta)$ were reported in parts per million (ppm), and coupling

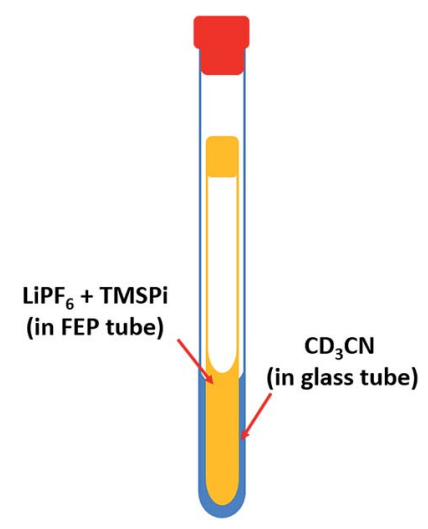

Fig. 1 Schematic plot of the NMR sample set-up to identify the reaction products of $\mathrm{LiPF}_{6}$ and $\mathrm{TMSP}$. The $\mathrm{LiPF}_{6}$ and TMSPi were sealed in the FEP tube; and the $\mathrm{CD}_{3} \mathrm{CN}$ was filled in the glass tube as a standard reference. constants ( $J$ values) were given in hertz $(\mathrm{Hz})$. All samples were prepared in an argon filled glovebox with pre-dried solvents $\left(\mathrm{H}_{2} \mathrm{O}\right.$ content less than $\left.10 \mathrm{ppm}\right)$. Fluorinated ethylene propylene (FEP) NMR tubes ( $\varnothing 3 \mathrm{~mm}$, Wilmad-labglass) were used to avoid any side reaction between the residual amount of HF and glass. The FEP tubes containing 200 to $300 \mu \mathrm{L}$ of samples were closed by a polytetrafluorethylene (PTFE) plug and placed in a glass NMR tube ( $\varnothing 5 \mathrm{~mm})$ containing $50 \mu \mathrm{L}$ of acetonitrile- $\mathrm{d}_{3}\left(\mathrm{CD}_{3} \mathrm{CN}\right.$, 99.8 at $\% \mathrm{~d}_{3}$, Sigma Aldrich). In this way, any contact between the deuterated solvent and reaction mixtures, which could produce unwanted products, was prohibited. A PTFE NMR cap was used to close the glass NMR tubes which were sealed by Parafilm ${ }^{\circledR}$ afterwards (Fig. 1).

\section{Results and discussion}

As reported by Yim et al., ${ }^{18}$ the Gibbs free energy of the reaction between TMSPi and LiF was calculated as $-34.1 \mathrm{kcal} \mathrm{mol}^{-1}$. It can thus be assumed that TMSPi would influence the equilibrium of the reaction: $\mathrm{LiPF}_{6} \rightleftharpoons \mathrm{LiF}+\mathrm{PF}_{5}$ by removing $\mathrm{LiF}$ and continuously promote the decomposition of $\mathrm{LiPF}_{6}$. As a result, TMSPi would be consumed by this reaction after a certain aging time and would have no longer beneficial effect on the cell performance.

The ${ }^{1} \mathrm{H}-\mathrm{NMR}$ spectra of two aged TMSPi containing electrolytes, which had been stored in glovebox for one week and for 45 days $\left(20{ }^{\circ} \mathrm{C}\right)$, respectively, were measured. Fig. 2a shows the spectrum of pure TMSPi, where $\mathrm{CD}_{3} \mathrm{CN}$ was used as solvent. Fig. $2 \mathrm{~b}$ and c illustrate the ${ }^{1} \mathrm{H}$-NMR spectra of LP47 electrolyte with $0.5 \mathrm{wt} \%$ TMSPi after one week and 45 days, respectively. In order to avoid any side reaction between $\mathrm{CD}_{3} \mathrm{CN}$ and electrolyte components, an experimental set-up, which is shown in Fig. 1, was used. The TMSPi containing electrolyte LP47 was placed in the FEP tube and $\mathrm{CD}_{3} \mathrm{CN}$ was filled in the glass tube. The ${ }^{1} \mathrm{H}$ NMR spectrum of the TMSPi containing electrolyte after one week of storage shows both signals of TMSPi and TMSF (Fig. 2b). The slight shift of the TMSPi signal from $0.2 \mathrm{ppm}$ (Fig. 2a) to 0.03 ppm (Fig. 2b and c) was caused by using different solvents. As already well known, the multiplet signal in ${ }^{19} \mathrm{~F}-\mathrm{NMR}$ spectrum at $-157 \mathrm{ppm}$ with ${ }^{1} J_{\mathrm{FH}}$ coupling constant of $7 \mathrm{~Hz}$ clearly demonstrates a considerable amount of dissolved TMSF in the solution. ${ }^{19}$ The aged TMSPi containing electrolyte, which was stored in a glovebox at $20{ }^{\circ} \mathrm{C}$ for 45 days, showed no presence of TMSPi in the electrolyte and only the TMSF could be observed in ${ }^{1} \mathrm{H}$-NMR spectrum (Fig. 2c).

The ${ }^{19} \mathrm{~F}$-NMR spectrum of the TMSPi containing electrolyte aged for 45 days (Fig. 3a) shows different sets of signals between $-80 \mathrm{ppm}$ and $-86 \mathrm{ppm}$ which are related to different fluorophosphates. ${ }^{20}$ A doublet at $-83.0 \mathrm{ppm}$ in ${ }^{19} \mathrm{~F}-\mathrm{NMR}$ spectrum ( 1 and $1^{\prime}$ ) which correlates with a triplet in ${ }^{31} \mathrm{P}-\mathrm{NMR}$ spectrum at $-20.1 \mathrm{ppm}\left({ }^{1} J_{\mathrm{PF}}=929 \mathrm{~Hz}\right.$, Fig. $\left.3 \mathrm{~b}\right)$ proves the formation of $\mathrm{OPF}_{2}(\mathrm{OH})$. In addition, the ${ }^{19} \mathrm{~F}-\mathrm{NMR}$ spectrum (Fig. 3a) shows two sets of doublets at $-84.04 \mathrm{ppm}$ and $-84.06 \mathrm{ppm}$ with ${ }^{1} J_{\mathrm{PF}}$ coupling constants of $967\left(2\right.$ and $\left.2^{\prime}\right)$ and 1005 (3 and $\left.3^{\prime}\right) \mathrm{Hz}$ respectively which are assigned to $\mathrm{OPF}(\mathrm{OMe})_{2}$ and $\mathrm{OPF}(\mathrm{OEt})_{2}$. However, due to the low signal intensity of the ${ }^{31} \mathrm{P}-\mathrm{NMR}$ spectrum (Fig. 3b), the related signals could not be determined. In 

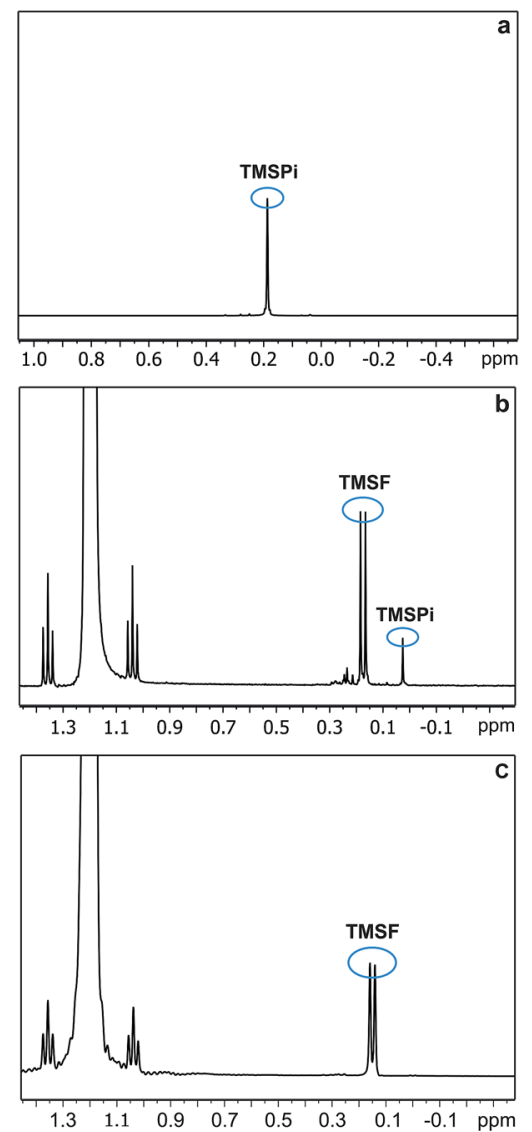

Fig. 2 The ${ }^{1} \mathrm{H}-\mathrm{NMR}$ spectra of pure TMSPi in $\mathrm{CD}_{3} \mathrm{CN}(\mathrm{a})$, and $0.5 \mathrm{wt} \%$ TMSPi containing LP47 electrolyte stored in a glovebox for one week (b) and for 45 days (c).

Fig. 3a, the singlet at -78.3 ppm cannot be assigned to any product.

The decrease of HF in the TMSPi containing electrolyte has already been confirmed by ${ }^{19} \mathrm{~F}-\mathrm{NMR} .{ }^{16,21}$ The TMSPi was thus considered as an effective HF scavenger. However, the high electron affinity of the TMS group may also attract other anions beside $\mathrm{F}^{-}$. In this work, a water contaminated LP47 electrolyte was used to evaluate the water scavenging ability of TMSPi. The water content in the contaminated LP47 electrolyte was $50 \mathrm{ppm}$. $0.5 \mathrm{wt} \%$ TMSPi was added and the electrolyte was stored at $20{ }^{\circ} \mathrm{C}$ for 12 hours. Afterwards, the water content of both electrolytes with and without TMSPi was measured by Karl-Fischer titration and compared. As summarized in Table 1, the TMSPicontaining electrolyte shows a decreased amount of water, indicating that TMSPi acted as a decontaminating agent to purify the electrolyte by removing the $\mathrm{HF}$ and $\mathrm{H}_{2} \mathrm{O}$.

As discussed in the work from Mai et al. ${ }^{15}$ the improvement in the cycling stability by using TMSPi was also attributed to a passivating CEI formed by oxidative electrolyte decomposition. The onset potential was at ca. $4.1 \mathrm{~V} v s$. $\mathrm{Li} / \mathrm{Li}^{+}$at a platinum electrode. ${ }^{15}$ In this work, as shown in Fig. 2, no TMSPi could be observed after 45 days storage. It is of great importance to find out whether a stable CEI could still be formed after all the TMSPi was consumed by the reaction with $\mathrm{HF}$ and $\mathrm{H}_{2} \mathrm{O}$.
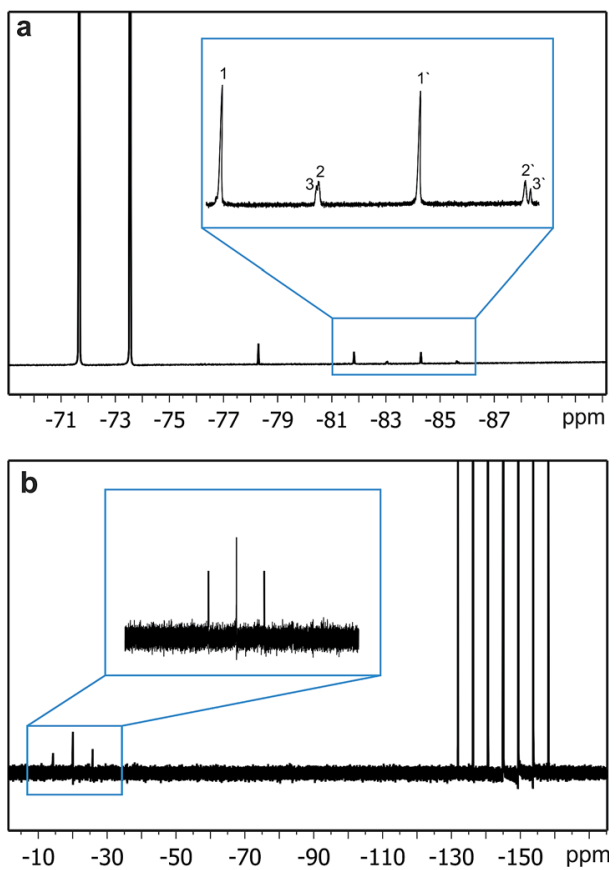

Fig. 3 (a) ${ }^{19} \mathrm{~F}-\mathrm{NMR}$ spectrum of the $0.5 \mathrm{wt} \%$ TMSPi containing LP47 electrolyte stored in glovebox for 45 days: 1 and $1^{\prime} \mathrm{OPF}_{2}(\mathrm{OH}) ; 2$ and $2^{\prime}$ $\left(\mathrm{OPF}(\mathrm{OMe})_{2}\right) ; 3$ and $3^{\prime}\left(\mathrm{OPF}(\mathrm{OEt})_{2}\right)(\mathrm{b}){ }^{31} \mathrm{P}-\mathrm{NMR}$ spectrum of the same sample.

Therefore, the oxidation stability of the baseline LP47 electrolyte, the fresh TMSPi containing LP47 electrolyte and the aged TMSPi containing LP47 electrolyte was determined with a platinum working electrode against a lithium counter electrode (shown in Fig. 4). To get close to the equilibrium state of the reaction, a relatively low scan rate of $0.1 \mathrm{mV} \mathrm{s}^{-1}$ (50 times lower than in the work of Mai et al.) was used.

As shown in Fig. 4, the oxidative decomposition of all three electrolytes started at approximately the same onset potential. Similar to the results obtained by Mai et al., the fresh TMSPi containing electrolyte clearly formed a passivating layer on the platinum electrode as the anodic current was much lower than the baseline electrolyte above $5.3 \mathrm{~V} v s$. $\mathrm{Li} / \mathrm{Li}^{+}$. However, the aged electrolyte containing TMSPi did not show this passivation behavior and the anodic current had a similar value as in the case of the baseline electrolyte. Obviously, the reaction products

Table 1 Water content in the contaminated LP47 electrolyte with and without the addition of $0.5 \mathrm{wt} \%$ TMSPi. The electrolytes were stored in a glovebox at $20^{\circ} \mathrm{C}$ for 12 hours

\begin{tabular}{|c|c|c|c|c|}
\hline \multirow[b]{2}{*}{ Measurement } & \multicolumn{2}{|c|}{$\begin{array}{l}\mathrm{LP} 47\left(\mathrm{H}_{2} \mathrm{O}\right. \\
\text { contaminated })\end{array}$} & \multicolumn{2}{|c|}{$\begin{array}{l}\mathrm{LP} 47\left(\mathrm{H}_{2} \mathrm{O} \text { contaminated }\right) \\
+0.5 \mathrm{wt} \% \mathrm{TMSPi}\end{array}$} \\
\hline & $\begin{array}{l}\text { Sample } \\
\text { mass }(\mathrm{g})\end{array}$ & $\mathrm{H}_{2} \mathrm{O}(\mathrm{ppm})$ & $\begin{array}{l}\text { Sample } \\
\text { mass (g) }\end{array}$ & $\mathrm{H}_{2} \mathrm{O}(\mathrm{ppm})$ \\
\hline 1 & 1.21579 & 44.00 & 1.32239 & 38.80 \\
\hline 2 & 1.13990 & 50.90 & 1.35221 & 32.20 \\
\hline Average & & 47.45 & & 35.50 \\
\hline
\end{tabular}




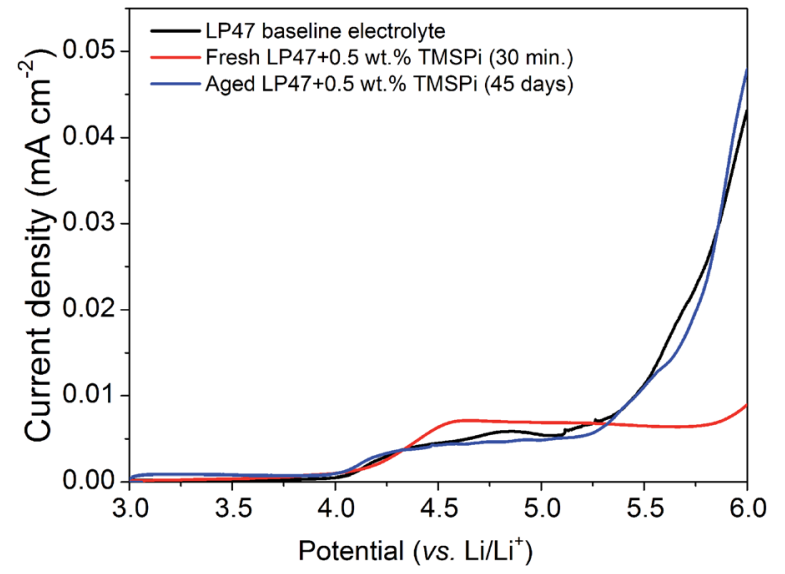

Fig. 4 Oxidation stability determination of the baseline LP47 electrolyte (black line), the fresh LP47 electrolyte containing TMSPi (red line) and the aged LP47 electrolyte containing TMSPi (blue line).

of TMSPi with HF or with other compounds, such as water, were not able to form a stable CEI. It is necessary to investigate the electrochemical performance of the aged TMSPi containing electrolyte in a full lithium ion cells to know whether the electrolyte additive still has a positive effect on the cycling stability.

The cycling stability of $\mathrm{LiNi}_{0.5} \mathrm{Co}_{0.2} \mathrm{Mn}_{0.3} \mathrm{O}_{2} /$ graphite full cells was investigated in the three electrolytes: the baseline LP47 electrolyte, the fresh TMSPi containing LP47 electrolyte and the aged TMSPi containing LP47 electrolyte (Fig. 5). The cut-off voltage range was set between $2.8 \mathrm{~V}$ and $4.6 \mathrm{~V}$. To prove the reproducibility of the cell performance, two cells with the aged TMSPi containing electrolyte are shown in Fig. 5 .

The reasons behind the fast capacity fading of the $\mathrm{LiNi}_{0.5^{-}}$ $\mathrm{Co}_{0.2} \mathrm{Mn}_{0.3} \mathrm{O}_{2} /$ graphite full cells charged up to $4.6 \mathrm{~V}$ had been previously studied. On one hand, the irreversible transformation of the $\mathrm{LiNi}_{0.5} \mathrm{Co}_{0.2} \mathrm{Mn}_{0.3} \mathrm{O}_{2}$ from the pristine

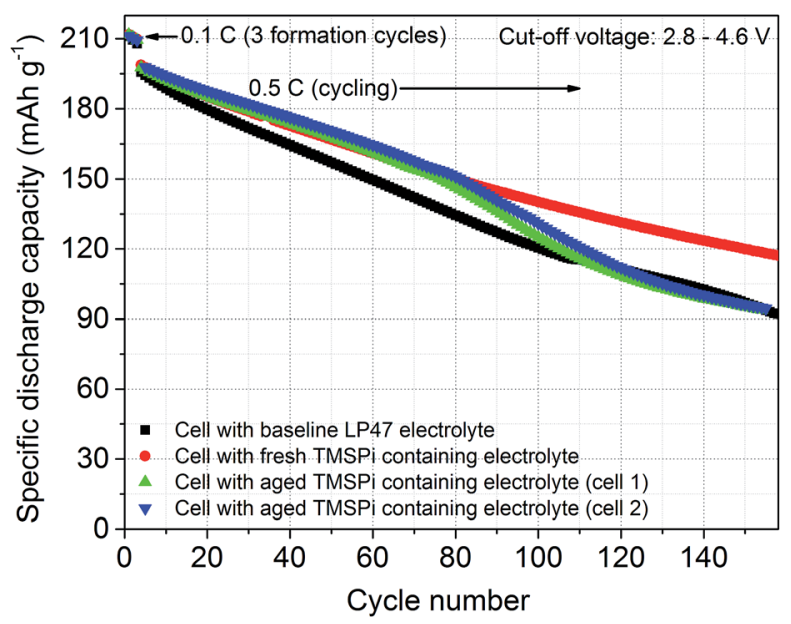

Fig. 5 Cycling stability of $\mathrm{LiNi}_{0.5} \mathrm{CO}_{0.2} \mathrm{Mn}_{0.3} \mathrm{O}_{2}$ /graphite full cells in the following electrolytes: baseline LP47 electrolyte (black square); freshly prepared TMSPi containing electrolyte (red dot); aged TMSPi containing electrolyte (green triangle and blue inverted triangle). Cut-off voltage ranging from $2.8 \mathrm{~V}$ to $4.6 \mathrm{~V}$. rhombohedral phase to a mixture of spinel and rock salt phase $\mathrm{e}^{22}$ significantly reduced the conductivity of the material. On the other hand, the carbonate based electrolytes could not resist the high cathode potential ${ }^{1}$ and experienced a continuous oxidative decomposition. In this work, all investigated cells were charged/ discharged within the same cut-off voltage window, so that the deterioration in the cycling stability caused by the phase transformation should be similar in each case. The difference in the cycling performance was thus determined by the electrolyte decomposition. During the first 70 cycles, the cells with fresh and aged TMSPi containing electrolytes showed similar specific discharge capacity ( $c a .156 \mathrm{~mA} \mathrm{~h} \mathrm{~g}^{-1}$ ) and capacity fading rate (Fig. 5). The cell with the baseline LP47 electrolyte showed a specific discharge capacity of $143 \mathrm{~mA} \mathrm{~h} \mathrm{~g} \mathrm{~g}^{-1}$ and a faster capacity fading. This could be explained by the fact that the TMSPi helped to "purify" the electrolyte by removing the HF and $\mathrm{H}_{2} \mathrm{O}$ contaminates. However, after 80 cycles, both cells with aged TMSPi containing electrolyte suffered from a faster capacity fading rate than the ones with the fresh TMSPi containing electrolyte. The better cycling stability of the cells with fresh TMSPi containing electrolyte could be attributed to the stable CEI layer formed in the presence of TMSPi. After 120 cycles, the discharge capacity of the cells with the aged TMSPi containing electrolyte decreased to the same level as the cell with the baseline electrolyte, showing that the aged TMSPi containing electrolyte failed to form an effective CEI to prevent further electrolyte oxidation.

Surface analysis by means of XPS was used to characterize the CEI formed by investigated electrolytes. In the $\mathrm{P} 2 \mathrm{p}$ spectra of the $\mathrm{LiNi}_{0.5} \mathrm{Co}_{0.2} \mathrm{Mn}_{0.3} \mathrm{O}_{2}$ cathode (Fig. 6), the peak at the higher binding energy (ca. $136.8 \mathrm{eV}$ ) corresponded to $\mathrm{LiPF}_{x}$, whereas the broad peak at the lower binding energy ( $c a .135 \mathrm{eV}$ ) originated from $\operatorname{LiPF}_{x} \mathrm{O}_{y}{ }^{5,23,24}$

Regarding the fluorophosphates compounds, the binding energy of the $\mathrm{P} 2 \mathrm{p}$ electrons is highly influenced by the attached elements or groups, ${ }^{25}$ e.g. $\mathrm{PF}_{x} \mathrm{O}_{y}{ }^{-}$has higher binding energy than $\mathrm{PO}_{4}{ }^{3-}{ }^{23,24}$ Thus, the fluorophosphates showed a broad peak in the P 2p spectra. A comparison between Fig. 6a and b showed that the CEI film, which was formed by the oxidative decomposition of TMSPi in the freshly prepared TMSPi containing electrolyte, contained more fluorophosphates than the CEI obtained by the baseline LP47 and the aged TMSPi containing LP47 electrolytes. The contents of $\mathrm{LiPF}_{x} \mathrm{O}_{y}$ (atomic ratio) in the CEI films formed in different electrolytes are listed in Table 2 .

The thickness of the CEI films at the different cathode surfaces was calculated from the obtained XPS measurement results and by means of the theory developed by Niehoff et $a .^{23,26}$ As shown in Table 2, the fresh TMSPi containing electrolyte enabled the formation of a CEI film of $10.5 \AA$, which was thinner than the CEI formed by decomposition of the other two electrolytes. All three CEI films contained a similar amount of $\mathrm{LiPF}_{x}$. However, the CEI formed by baseline LP47 had ca. 0.9 at\% $\mathrm{LiPF}_{x} \mathrm{O}_{y}$, while the CEI formed by the fresh TMSPi containing electrolyte possessed as high as ca. 6.7 at\% $\operatorname{LiPF}_{x} \mathrm{O}_{y}$. Based on the better electrochemical performance, the CEI film with more fluorophosphates could be assumed to be more 


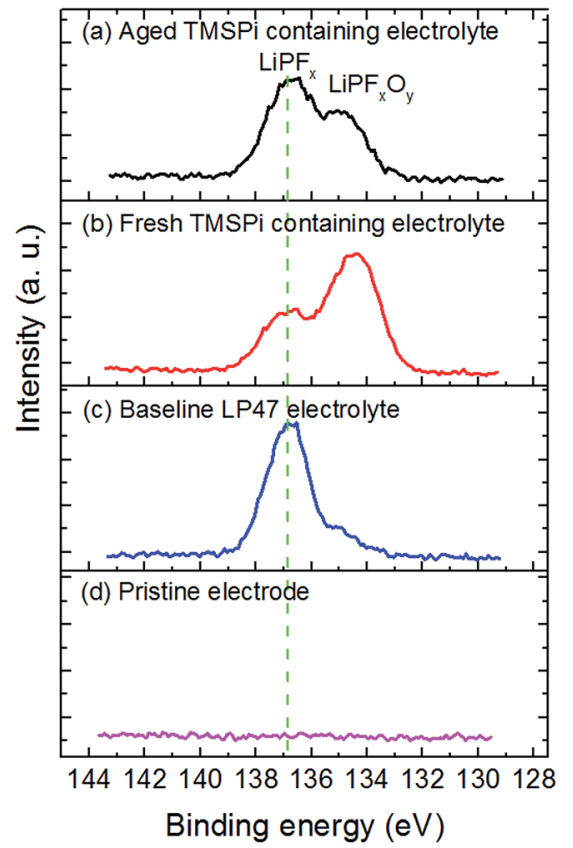

Fig. 6 P 2p spectra of the $\mathrm{LiNi}_{0.5} \mathrm{CO}_{0.2} \mathrm{Mn}_{0.3} \mathrm{O}_{2}$ cathode (after 150 cycles, discharged) with (a) aged TMSPi-containing electrolyte, (b) fresh TMSPi containing electrolyte, (c) baseline LP47 electrolyte and (d) a pristine electrode without exposure to the electrolyte.

robust and compact and thus effectively diminished the oxidation of the electrolytes.

The thickness of the CEI formed by the aged TMSPi containing electrolyte increased to $21.4 \AA$, while the amount of fluorophosphates decreased to 1.50 at $\%$. The CEI built by the aged TMSPi containing LP47 electrolyte was less stable during long-term cycling.

Consequently, it is important to investigate the reaction between TMSPi and $\mathrm{LiPF}_{6}$ to find out why less fluorophosphates remained after aging of the electrolyte. To avoid the side reaction with the carbonate solvents, the TMSPi was directly mixed with $\mathrm{LiPF}_{6}$ in a molar ratio of $5: 3$, as it was suspected that the TMSPi reacted with $\mathrm{PF}_{5}$. The mixture was sealed in plastic vials (polypropylene, Shimadzu®) for the GC-MS measurement and stored in glovebox for two weeks at $20{ }^{\circ} \mathrm{C}$. The product was investigated by NMR. The headspace gas was collected by a syringe and then injected into the GC-MS device. The mass spectrum is shown in Fig. 7. As the EI mode was applied to charge the molecule fragments, the obtained $\mathrm{m} / \mathrm{z}$ values directly indicated the molecular weight of the gas species.

Table 2 Thickness of the CEI films on $\mathrm{LiNi}_{0.5} \mathrm{CO}_{0.2} \mathrm{Mn}_{0.3} \mathrm{O}_{2}$ cathodes cycled in different electrolytes, as well as the atomic ratio of the LiPF and $\mathrm{LiPF}_{x} \mathrm{O}_{y}$ in each CEI film. "Dev." stands for "Mean deviation"

\begin{tabular}{llllll}
\hline Electrolyte & $\begin{array}{l}\text { Average } \\
\text { thickness (̊) }\end{array}$ & $\begin{array}{l}\mathrm{LiPF}_{x} \\
\text { (at\%) }\end{array}$ & $\begin{array}{l}\text { Dev. } \\
\text { (at\%) }\end{array}$ & $\begin{array}{l}\mathrm{LiPF}_{x} \mathrm{O}_{y} \\
\text { (at\%) }\end{array}$ & $\begin{array}{l}\text { Dev. } \\
\text { (at\%) }\end{array}$ \\
\hline Baseline LP47 & 31.6 & 3.0 & 0.3 & 0.9 & 0.4 \\
LP47 + TMSPi (fresh) & 10.5 & 3.1 & 0.1 & 6.7 & 0.1 \\
LP47 + TMSPi (aged) & 21.4 & 2.6 & 0.2 & 1.50 & 0.05
\end{tabular}

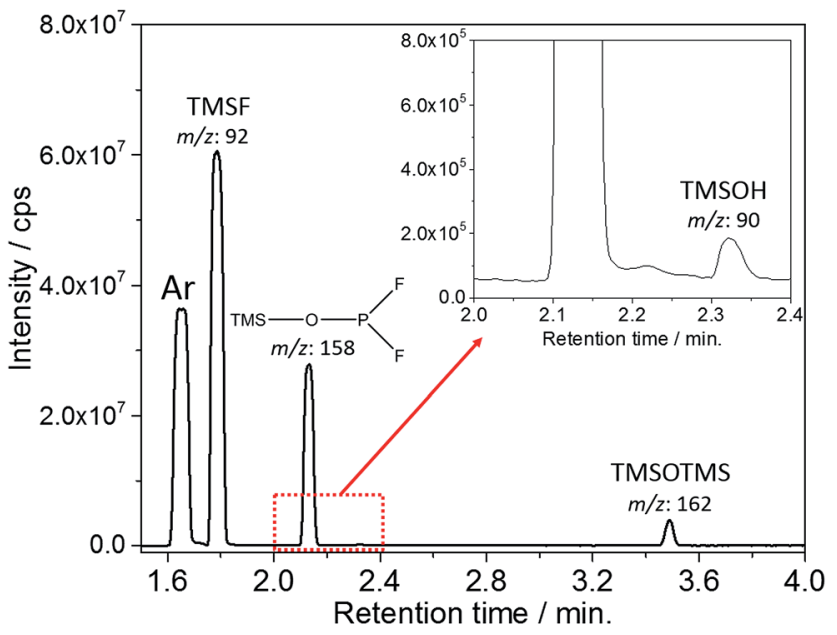

Fig. 7 GC-MS of the headspace gas generated from the reaction between $\mathrm{LiPF}_{6}$ and TMSPi (molar ratio was $3: 5$ ).

Besides TMSF, TMSOH and TMSOTMS ${ }^{18}$ signals, one more peak with the $\mathrm{m} / \mathrm{z}$ value of 158 was observed at the retention time of $2.1 \mathrm{~min}$ (Fig. 7). According to the possible reaction routines, this peak was assigned to trimethylsilyl difluorophosphinite ((TMSO) $\left.\mathrm{PF}_{2}\right)$, which was firstly synthesized and reported by Cavell et al. ${ }^{27}$ in 1973. In the reaction with $\mathrm{LiPF}_{6}$, the $\mathrm{POF}_{2}{ }^{-}$groups were obtained from the TMSPi via the exchange of the $\mathrm{P}-\mathrm{O}^{-}$bond and the $\mathrm{P}-\mathrm{F}$ bond (shown in Scheme 1). The $\mathrm{POF}_{2}{ }^{-}$was bound to the TMS groups and formed (TMSO) $\mathrm{PF}_{2}$, which had a relatively low boiling point ${ }^{27}$ and could be detected by GC-MS.

The existence of the (TMSO) $\mathrm{PF}_{2}$ could also be confirmed by the ${ }^{19}$ F-NMR spectrum (Fig. 8a) of the reaction product of $\mathrm{LiPF}_{6}$ and TMSPi. A doublet at $-33.5 \mathrm{ppm}$ in ${ }^{19} \mathrm{~F}$-NMR spectrum and a triplet at $113.2 \mathrm{ppm}$ in ${ }^{31} \mathrm{P}$-NMR with ${ }^{1} J_{\mathrm{PF}}$ coupling constant of $1032 \mathrm{~Hz}$ (Fig. 8b) were in agreement with previously reported NMR data. ${ }^{27}$ Furthermore, two sets of doublets in ${ }^{19} \mathrm{~F}$-NMR spectrum (Fig. 8a) at -84.0 ppm (broad signals, 1 and $1^{\prime}$ ) and $-73.3 \mathrm{ppm}\left(2\right.$ and $\left.2^{\prime}\right)$ with ${ }^{1} J_{\mathrm{PF}}$ coupling constant of $980 \mathrm{~Hz}$ and $925 \mathrm{~Hz}$, respectively, could be assigned to the formation of (TMSO) $\mathrm{POF}_{2}$ and (TMSO) ${ }_{2} \mathrm{POF}^{28}$ (structure shown in Fig. 8d). TMSF and a very small amount of $\operatorname{LiPF}_{6}\left(3\right.$ and $\left.3^{\prime}\right)$ were detectable in the ${ }^{19}$ F-NMR spectrum (Fig. 8a). The corresponding signals also appeared in the ${ }^{31} \mathrm{P}-\mathrm{NMR}$ spectrum (Fig. 8b) at $-17.8 \mathrm{ppm}$ for (TMSO)POF $\mathrm{PO}_{2}$ as a broad triplet $\left(1,1^{\prime}\right.$ and $1^{\prime \prime}$ ) and at $-27.1 \mathrm{ppm}$ for (TMSO) ${ }_{2} \mathrm{POF}$ as a doublet ( 2 and $2^{\prime}$ ). Besides, the ${ }^{31} \mathrm{P}$-NMR spectrum confirmed the formation of tris(trimethylsilyl) phosphate $\left((\mathrm{TMSO})_{3} \mathrm{PO}\right)$ and tetrakis (trimethylsilyl) diphosphate ester ((TMSO $)_{2} \mathrm{OPOPO}(\mathrm{OTMS})_{2}$, structure shown in Fig. 8d) as a singlet at -27.3 ppm (Fig. 8b, signal 3) and $-30.5 \mathrm{ppm}$ (Fig. 8b, signal 4), respectively. ${ }^{29} \mathrm{~A}$ small amount of (TMSO) ${ }_{2} \mathrm{PHO}$ (Fig. 8c, structure shown in Fig. 8d) was also produced in the reaction and could be assigned to a doublet in ${ }^{1} \mathrm{H}-\mathrm{NMR}$ spectrum at $6.8 \mathrm{ppm}$ ( 1 and $1^{\prime}$ ) with a ${ }^{1} J_{\mathrm{PH}}$ coupling constant of $714 \mathrm{~Hz}$ which was in correlation with a doublet in the ${ }^{31} \mathrm{P}$-NMR spectrum at -13.6 ppm $\left(5\right.$ and $\left.5^{\prime}\right) .{ }^{29}$ 

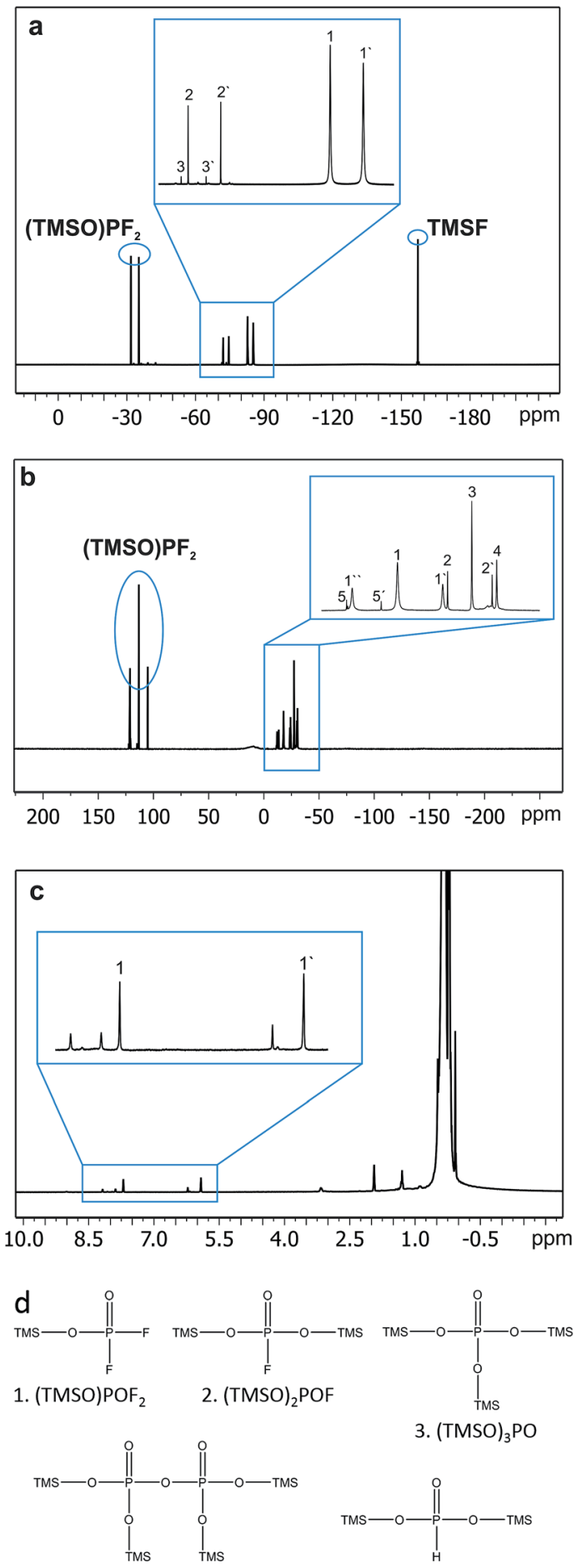

4. $(\mathrm{TMSO})_{2} \mathrm{OPOPO}(\mathrm{TMSO})_{2}$

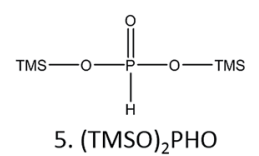

Fig. 8 NMR spectra of the reaction products of $\mathrm{LiPF}_{6}$ and TMSPi. (a) ${ }^{19} \mathrm{~F}-\mathrm{NMR}: 1$ and $1^{\prime}$ (TMSO)POF $2 ; 2$ and $2^{\prime}$ (TMSO) 2 POF. (b) ${ }^{31} \mathrm{P}-\mathrm{NMR}: 1$, $1^{\prime}$ and $1^{\prime \prime}\left(\mathrm{TMSO}^{\prime} \mathrm{POF}_{2} ; 2\right.$ and $2^{\prime}(\mathrm{TMSO})_{2} \mathrm{POF} ; 3$ (TMSO) ${ }_{3} \mathrm{PO} ; 4$ (TMSO) ${ }_{2} \mathrm{OPOP}(\mathrm{OTMS})_{2} ; 5$ and $5^{\prime}(\mathrm{TMSO})_{2} \mathrm{PHO}$. (c) ${ }^{1} \mathrm{H}-\mathrm{NMR}: 1$ and $1^{\prime}$ $(\mathrm{OTMS})_{2} \mathrm{PHO}$. (d) The schematic structure of the compounds found in the NMR analysis.

Based on the products observed by GC-MS and NMR, it is clearly shown that various TMS containing fluorophosphates have been formed. As a result, the polarity and reactivity of these fluorophosphates dramatically decreased and could not take part in the formation of an effective CEI film. The mechanism of the reaction between TMSPi and $\mathrm{LiPF}_{6}$ is proposed and presented in Scheme 1. In order to support the proposed mechanism and reaction steps, computational and theoretical chemistry approaches are in frame of our ongoing investigations. Not all the products are mentioned in Scheme 1, while only the formation of (TMSO) $\mathrm{PF}_{2}$ and (TMSO) $\mathrm{POF}_{2}$ as two key products are taken in consideration.

As the binding energy of $\mathrm{Si}-\mathrm{F}$ bond is higher than the $\mathrm{Si}-\mathrm{O}$ bond, ${ }^{18}$ the TMS groups in the TMSPi will react with the $\mathrm{F}^{-}$from $\mathrm{LiPF}_{6}$, resulting in the formation of TMSF and $\mathrm{P}-\mathrm{O}^{-}$bond. Afterwards, an exchange reaction between $\mathrm{P}-\mathrm{O}^{-}$bond and $\mathrm{P}-\mathrm{F}$ bond in $\mathrm{PF}_{5}$ results in the formation of the highly reactive $\mathrm{POF}_{3}$. $\mathrm{PF}_{2} \mathrm{O}_{2}{ }^{-}\left(\mathrm{PF}_{x} \mathrm{O}_{y}{ }^{-}\right)$can be formed by a further exchange reaction between the $\mathrm{P}-\mathrm{O}^{-}$bond and $\mathrm{P}-\mathrm{F}$ (from $\mathrm{POF}_{3}$ ). Due to the high anion affinity of the TMS groups, the TMSPi could react with various $\mathrm{PF}_{x} \mathrm{O}_{y}{ }^{-}$moieties and generate the products illustrated in Fig. 8, e.g. the (TMSO) $\mathrm{POF}_{2}$. The major product of the reaction between TMSPi and $\mathrm{LiPF}_{6}$ after two weeks is $\mathrm{TMSOPF}_{2}$, which has been detected by GC-MS analysis (Fig. 7). Therefore, the $\mathrm{PO}_{3}{ }^{3-}$ group from TMSPi is consumed by the reaction with $\mathrm{LiPF}_{6}$ and do not take part in the formation of the CEI. In the aged TMSPi containing electrolyte, the CEI film contains less fluorophosphate components than the CEI formed in the freshly prepared TMSPi containing electrolyte due to the formation of various TMS containing phosphates and fluorophosphates. Moreover, the concentration of $\mathrm{LiPF}_{6}$ is also diminished by this side reaction with TMSPi, resulting in the loss of charge carriers in the electrolyte.

\section{Conclusions}

A freshly prepared TMSPi containing LP47 electrolyte ( $1 \mathrm{M} \mathrm{LiPF}_{6}$ in a mixture of EC/DEC $3: 7$ (weight ratio)) shows a significant improvement to the cycling stability of the $\mathrm{LiNi}_{0.5} \mathrm{Co}_{0.2} \mathrm{Mn}_{0.3} \mathrm{O}_{2} /$ graphite lithium ion cells charged to $4.6 \mathrm{~V}$. Due to its high anion affinity, the TMS group diminishes the HF and water content in the investigated electrolyte. A thin and robust CEI which contains more fluorophosphates can be formed in presence of TMSPi. From this point of view, TMSPi can be applied as an effective electrolyte additive.

However, after aging at $20{ }^{\circ} \mathrm{C}$ for 4 weeks, no TMSPi can be detected in the electrolyte anymore. It has been confirmed that TMSPi facilitates the decomposition of the electrolyte salt $\mathrm{LiPF}_{6}$, which reduces the content of the conducting lithium salt in the electrolyte. The fluorophosphates generated from the decomposition of $\mathrm{LiPF}_{6}$ are captured by the highly electrophilic TMS groups, and thus cannot form a stable CEI anymore. Based on the reaction products between $\mathrm{LiPF}_{6}$ and TMSPi, a failure mechanism of the TMSPi in the $\mathrm{LiPF}_{6}$ containing carbonate electrolytes has been proposed. In conclusion, TMSPi has certain lifetime limit when being used as an additive in the $\mathrm{LiPF}_{6}$ based carbonate electrolytes, which means the TMSPi containing electrolyte can only be used within a short time after the addition of TMSPi. Its beneficial effect of improving the cycling stability of the cells deteriorates upon aging. 


\section{Acknowledgements}

The authors would like to thank Dr John Lin (Amperex Technology Limited) for the financial funding, as well as for the support of $\mathrm{LiNi}_{0.5} \mathrm{Co}_{0.2} \mathrm{Mn}_{0.3} \mathrm{O}_{2}$ and graphite samples.

\section{References}

1 R. Wagner, N. Preschitschek, S. Passerini, J. Leker and M. Winter, J. Appl. Electrochem., 2013, 43, 481-496.

2 S. Y. Ha, J. G. Han, Y. M. Song, M. J. Chun, S. I. Han, W. C. Shin and N. S. Choi, Electrochim. Acta, 2013, 104, 170-177.

3 E. Wang, D. Ofer, W. Bowden, N. Iltchev, R. Moses and K. Brandt, J. Electrochem. Soc., 2000, 147, 4023-4028.

4 M. Grutzke, V. Kraft, B. Hoffmann, S. Klamor, J. Diekmann, A. Kwade, M. Winter and S. Nowak, J. Power Sources, 2015, 273, 83-88.

5 K. Edstrom, T. Gustafsson and J. O. Thomas, Electrochim. Acta, 2004, 50, 397-403.

6 D. R. Gallus, R. Schmitz, R. Wagner, B. Hoffmann, S. Nowak, I. Cekic-Laskovic, R. W. Schmitz and M. Winter, Electrochim. Acta, 2014, 134, 393-398.

7 M. Winter, Z. Phys. Chem., 2009, 223, 1395-1406.

8 D. R. Gallus, R. Wagner, S. Wiemers-Meyer, M. Winter and I. Cekic-Laskovic, Electrochim. Acta, 2015, 184, 410-416.

9 X. X. Zuo, C. J. Fan, J. S. Liu, X. Xiao, J. H. Wu and J. M. Nan, J. Electrochem. Soc., 2013, 160, A1199-A1204.

10 Z. J. Cai, Y. B. Liu, J. H. Zhao, L. Li, Y. M. Zhang and J. Zhang, J. Power Sources, 2012, 202, 341-346.

11 D. J. Lee, D. Im, Y. G. Ryu, S. Lee, J. Yoon, J. Lee, W. Choi, I. Jung, S. Lee and S. G. Doo, J. Power Sources, 2013, 243, 831-835.

12 A. Wursig, H. Buqa, M. Holzapfel, F. Krumeich and P. Novak, Electrochem. Solid-State Lett., 2005, 8, A34-A37.

13 J. Demeaux, D. Lemordant, M. Caillon-Caravanier, H. Galiano and B. Claude-Montigny, Electrochim. Acta, 2013, 89, 163-172.
14 Z. D. Li, Y. C. Zhang, H. F. Xiang, X. H. Ma, Q. F. Yuan, Q. S. Wang and C. H. Chen, J. Power Sources, 2013, 240, 471-475.

15 S. W. Mai, M. Q. Xu, X. L. Liao, J. N. Hu, H. B. Lin, L. D. Xing, Y. P. Liao, X. P. Li and W. S. Li, Electrochim. Acta, 2014, 147, 565-571.

16 Y. M. Song, J. G. Han, S. Park, K. T. Lee and N. S. Choi, J. Mater. Chem. A, 2014, 2, 9506-9513.

17 N. N. Sinha, J. C. Burns and J. R. Dahn, J. Electrochem. Soc., 2014, 161, A1084-A1089.

18 Y. K. Han, J. Yoo and T. Yim, J. Mater. Chem. A, 2015, 3, 10900-10909.

19 E. L. Myers, C. P. Butts and V. K. Aggarwal, Chem. Commun., 2006, 4434-4436.

20 C. L. Campion, W. T. Li and B. L. Lucht, J. Electrochem. Soc., 2005, 152, A2327-A2334.

21 N. S. Choi, J. G. Han, S. Y. Ha, I. Park and C. K. Back, RSC Adv., 2015, 5, 2732-2748.

22 S. K. Jung, H. Gwon, J. Hong, K. Y. Park, D. H. Seo, H. Kim, J. Hyun, W. Yang and K. Kang, Adv. Energy Mater., 2014, 4, 1300787.

23 P. Niehoff and M. Winter, Langmuir, 2013, 29, 15813-15821.

24 E. Fluck and D. Weber, Z. Naturforsch., B: Anorg. Chem., Org. Chem., 1974, 29, 603-607.

25 M. Pelavin, D. N. Hendrickson, J. M. Hollander and W. L. Jolly, J. Phys. Chem., 1970, 74, 1116-1121.

26 P. Niehoff, S. Passerini and M. Winter, Langmuir, 2013, 29, 5806-5816.

27 R. G. Cavell, R. D. Leary, A. R. Sanger and A. j. Tomlinso, Inorg. Chem., 1973, 12, 1374-1380.

28 R. G. Cavell, A. j. Tomlinso and R. D. Leary, Inorg. Chem., 1972, 11, 2573-2578.

29 L. A. Wessjohann and M. A. Dessoy, Polyhedron, 2014, 70, 133-137. 